\title{
Molecular characteristics of the ompA gene of serotype B Chlamydia trachomatis in Qinghai Tibetan primary school students
}

\author{
Xue Li, Shaoya Zhang, Qingfeng Liang, Mei Wang, Ailian Hu, Xiuyuan Li, Benshan Yang, \\ Mingxin Zhang, Ningli Wang \& Xinxin Lu
}

Beijing Institute of Ophthalmology, Beijing Tongren Eye Center, Beijing Tongren Hospital, Capital Medical University, Beijing Key Laboratory of Ophthalmology and Visual Sciences, Beijing 100005, China

Received April 3, 2016; accepted April 15, 2016

\begin{abstract}
To study the molecular characteristics of Chlamydia trachomatis, the major outer membrane protein gene (ompA) of $C$. trachomatis from primary school students with trachoma residing in the Qinghai Tibetan area was sequenced and compared with the same serotype in GenBank. In Jianshetang Primary School and Galeng Central Primary School in the Galeng Tibetan Township of Qinghai Haidong Sala Autonomous County, scraped samples were collected from the upper tarsal conjunctiva and lower conjunctival sac of both eyes of 45 students with trachoma, stored at $4{ }^{\circ} \mathrm{C}$, and transported to Beijing Tongren Hospital by air within $24 \mathrm{~h}$. The samples were screened for $C$. trachomatis by real-time PCR. The ompA gene from the $C$. trachomatis-positive samples was amplified by nested PCR. The serotype was confirmed by National Center for Biotechnology Information (NCBI) BLAST search and homology analysis. The entire ompA gene sequence was compared with the corresponding gene sequences of serotype B strains available in GenBank. Of the 45 students aged 6-13 years with trachoma, $26 \mathrm{C}$. trachomatis-positive students were identified by the initial real-time PCR screening (average age, $(9.09 \pm 1.63)$ years; sex ratio, 1.0), accounting for $57.78 \%$ (26/45). The cycle threshold values for real-time PCR were 16.79-37.77. Half (13/26) of $C$. trachomatis-positive students had a bacterial copy number of $>10^{5}$. The compliance rate of the ompA gene sequences with the $C$. trachomatis serotype B strains in GenBank was up to $99 \%$. Two novel genetic mutations were found when the ompA gene was compared with those of the 11 serotype B strains in GenBank. The two non-synonymous mutations were located at (i) position 271 in the second constant domain, an adenine (A) to guanine $(\mathrm{G})$ substitution (ACT $\rightarrow$ GCT), changing the amino acid at position 91 from threonine to alanine ( $\mathrm{Thr} \rightarrow \mathrm{Ala}$ ) in all 26 strains; and (ii) position 887 in the fourth variable domain, a cytosine (C) to thymine (T) substitution (GCA $\rightarrow$ GTA), changing the amino acid at residue 296 from alanine to valine (Ala $\rightarrow$ Val) in four of the 26 strains. Six mutations were identified relative to ATCC VR-573. The strains could be divided into two gene clusters according to the mutation at nucleotide position 887: CQZ-1 (China Qinghai Tibetan-1) and CQZ-2 (China Qinghai Tibetan-2). We thus detected two novel serotype B mutant strains of $C$. trachomatis among study subjects with trachoma.
\end{abstract}

Chlamydia trachomatis, major outer membrane protein gene, sequencing, homology analysis

Citation: $\quad$ Li, X., Zhang, S., Liang, Q., Wang, M., Hu, A., Li, X., Yang, B., Zhang, M., Wang, N., and Lu, X. (2016). Molecular characteristics of the ompA gene of serotype B Chlamydia trachomatis in Qinghai Tibetan primary school students. Sci China Life Sci 59, 561-570. doi: $10.1007 / \mathrm{s} 11427-016-5059-9$

\section{INTRODUCTION}

Chlamydia trachomatis was first confirmed to cause trachoma by chick embryo culture in China in 1956. With

*Corresponding author (email: luxinxin2009@126.com) decades of effort and the implementation of the surgery, antibiotics, facial cleanliness, and environmental improvements (SAFE) strategy, blinding trachoma was eliminated as a public health threat in China in 2015 (Wang et al., 2015). However, China holds a vast territory with imbal- 
anced economic development, and sporadic cases of trachoma have been reported in its remote regions. Therefore, prevention and control of local epidemics and recurrence of sporadic cases have become an important issue. In the previous epidemiological investigation, follicular trachoma (TF) among primary school students in Qinghai province was less than $5 \%$, but there are still some sporadic cases. In order to study the characteristics of current Chlamydia trachomatis, conjunctival swab sampling was carried out among primary school students aged 6-13 years with trachoma, the biological characteristics of $C$. trachomatis were determined by nucleic acid analysis by genotyping and sequencing of the ompA gene, gene homology analysis, and cell culture in 2015 .

\section{RESULTS}

\section{General information}

Among 45 enrolled students with trachoma according to the simplified trachoma grading system developed by the World Health Organization (WHO), 26 were positive for $C$. trachomatis according to real-time PCR: 8 from Jianshetang Primary School and 18 from Central Primary School. The male:female ratio was $1: 1$, and the age range was 6-13 years, with an average age of $(9.09 \pm 1.63)$ years (Table 1$)$. There were no significant differences in vision, redness, eye pain, or other symptoms among the affected children. Fifteen children showed more than five trachoma follicles in the upper eyelid $(57.69 \%)$, whereas 11 had fewer than five trachoma follicles $(42.31 \%)$, but the difference was not statistically significant $(P>0.05)$. The details are given in Table 1.

\section{Chlamydia trachomatis detected by real-time PCR}

The detection rate of $C$. trachomatis with the initial real-time PCR screening was $57.78 \%$ (26/45). Among C. trachomatis-positive students, $53.85 \%(14 / 26)$ were positive for $C$. trachomatis in both eyes, $34.62 \%(9 / 26)$ in one eye, and $11.54 \%(3 / 26)$ in the conjunctival sac only. The number of $C$. trachomatis students in Jianshetang Primary School was 8 , identifying one child with one infected eye and seven children with infection in both eyes. The number of C. trachomatis students in Central Primary School was 18, identifying 8 children with infection in only one eye, 7 children with infection in both eyes, and 3 children with an infected conjunctival sac only. Half of $C$. trachomatis-positive students $(50 \%, 13 / 26)$ had a high copy number of $C$. trachomatis (Figure 1).

\section{Serotype of $C$. trachomatis and homology analysis of the ompA gene}

After sequencing the ompA gene, we compared it with the sequences in NCBI's GenBank with a BLAST search. The 26 strains were confirmed as serotype $\mathrm{B}$, with a coincidence rate of $99 \%$. Eleven prototype strains sourced from the United States, the United Kingdom, Tanzania, the Gambia, and Russia were available in GenBank for comparison. Table 2 describes the nucleotide sequence variations in ompA and the corresponding amino acid changes. Two novel mutations were detected.

The strains were designated CQZ-1 (China Qinghai Tibetan-1) and CQZ-2 (China Qinghai Tibetan-2) according to the mutation at position 887 . The features of CQZ-1 were as follows: one non-synonymous mutation of adenine (A) to guanine $(\mathrm{G})$ (ACT $\rightarrow \mathrm{GCT}$ ) at position 271 in the second conserved domain, causing an amino acid to change from threonine to alanine at residue 91, which was found in all 26 specimens from both schools (Figure S1 in Supporting Information). The features of CQZ-2 were as follows: two mutations, namely, the aforementioned non-synonymous mutation at position 271 and another at position 887 in the fourth variable domain-a cytosine (C) to thymine (T) (GCA $\rightarrow$ GTA) substitution, causing an amino acid to change from alanine to valine at position 296-found in four strains, only from Central Primary School (Figure S1 in Supporting Information). The sequence data for the two genetic variants were submitted to GenBank under accession numbers KU737520 and KU737521 on February 17, 2016. Compared with ATCC VR-573, 6 mutations locating at nucleotide positions 216, 268, 271, 286, 287, and 887 were detected. Most of the mutations occurred in the first and fourth variable domains or the second conserved domain (Table 2). The different mutations of 37 strains are shown in Figure 2.

\section{DISCUSSION}

Trachoma is an important infectious ocular disease in children in developing countries, and when severe, it can lead to corneal and conjunctival scarring and even blindness (Taylor et al., 2014). The infection ratio of trachoma may reflect the local economic conditions, sanitation, and capacity to avoid the disease. Therefore, prevention and control of local epidemics and recurrence of sporadic cases have become an important issue.

In this study, we detected 26 cases of positive $C$. trachomatis with real-time PCR and serotype B was identified in these $C$. trachomatis cases. At present, C. trachomatis is divided into serotypes A-L, which can cause conjunctivitis, reproductive-tract infection, venereal granuloma, neonatal pneumonia, active arthritis and other diseases. Trachoma is closely associated with serotypes A, B, Ba, and C (Last et al., 2014; Ishak et al., 2015). C. trachomatis remains an epidemic in various countries, and Canada is the only high-income country with a trachoma prevalence of $>5 \%$ (Shattock et al., 2015). Active trachoma exists in a number of areas in Asia and Africa and other developing countries (Last et al., 2014; King et al., 2013; Nigusie et al., 2015; Burton et al., 2010), and a great number of studies have shown $C$. trachomatis serotypes differ across regions. For 
Table 1 General information of the 45 children with trachoma ${ }^{\text {a) }}$

\begin{tabular}{|c|c|c|c|c|c|c|c|c|c|c|c|c|}
\hline \multirow{2}{*}{ Schools } & \multirow{2}{*}{ Sample NO. } & \multirow{2}{*}{ Sex } & \multirow{2}{*}{ Age } & \multicolumn{2}{|c|}{ Vision } & \multirow{2}{*}{ Congestion } & \multirow{2}{*}{ Eye pain } & \multicolumn{2}{|c|}{$\begin{array}{c}\text { Trachoma } \\
\text { Follicle (unit) }\end{array}$} & \multicolumn{3}{|c|}{ Chlamydia trachomatis } \\
\hline & & & & OD & OS & & & OD & OS & OD & OS & Conjunctival sac \\
\hline \multirow{14}{*}{$\begin{array}{c}\text { Jianshetang } \\
\text { Primary School }\end{array}$} & 101 & Female & 9 & 5 & 5 & + & + & 1 & 2 & + & + & - \\
\hline & 102 & Female & 11 & 5.1 & 5.1 & + & + & $>5$ & $>5$ & + & + & - \\
\hline & 103 & Male & 10 & 5 & 4.9 & + & + & 1 & 3 & + & + & - \\
\hline & 104 & Male & 10 & 4.8 & 4.9 & + & + & 2 & $>5$ & + & + & - \\
\hline & 105 & Female & 9 & 5 & 5 & + & + & 4 & $>5$ & - & - & - \\
\hline & 106 & Female & 9 & 5 & 5.1 & + & + & 2 & $>5$ & - & + & - \\
\hline & 107 & Female & 8 & 5 & 4.8 & + & + & 3 & 4 & - & - & - \\
\hline & 108 & Male & 8 & 5 & 5 & + & + & 2 & 4 & - & - & - \\
\hline & 109 & Female & 8 & 5 & 5 & + & + & 3 & 2 & - & - & - \\
\hline & 110 & Male & 12 & 4.8 & 4.9 & + & + & 0 & 2 & - & - & - \\
\hline & 111 & Male & 11 & 5 & 5 & + & + & $>5$ & $>5$ & + & + & - \\
\hline & 112 & Male & 13 & 4.9 & 4.8 & + & + & 5 & 5 & + & + & - \\
\hline & 113 & Male & 10 & 5 & 5 & + & + & 5 & 5 & + & + & - \\
\hline & 114 & Female & 11 & 5 & 4.9 & + & + & 5 & $>5$ & - & - & - \\
\hline \multirow{31}{*}{$\begin{array}{c}\text { Central } \\
\text { Primary School }\end{array}$} & 118 & Female & 7 & 5 & 5 & + & + & 3 & 4 & + & + & + \\
\hline & 119 & Female & 10 & 5 & 5 & + & + & 5 & 3 & + & + & + \\
\hline & 120 & Male & 8 & 4.9 & 4.8 & + & + & $>5$ & 5 & + & + & + \\
\hline & 121 & Male & 8 & 5 & 5 & + & + & 1 & 1 & - & - & + \\
\hline & 122 & Female & 7 & 5 & 5 & + & + & 5 & 5 & - & - & + \\
\hline & 123 & Male & 7 & 5 & 5 & + & + & 5 & 5 & + & - & + \\
\hline & 124 & Male & 9 & 5.1 & 5.1 & + & + & 1 & 3 & - & + & + \\
\hline & 125 & Male & 8 & 5 & 4.9 & + & + & $>5$ & $>5$ & - & - & - \\
\hline & 126 & Female & 8 & 4.8 & 4.9 & + & + & 4 & 4 & + & - & + \\
\hline & 127 & Female & 7 & 5 & 5 & + & + & 1 & 3 & - & - & + \\
\hline & 128 & Male & 9 & 5 & 5.1 & + & + & 5 & $>5$ & - & - & - \\
\hline & 129 & Female & 10 & 5 & 4.8 & + & + & 3 & 1 & - & - & - \\
\hline & 130 & Male & 11 & 5 & 4.9 & + & + & 1 & 2 & - & - & - \\
\hline & 131 & Female & 9 & 5 & 5 & + & + & 5 & $>5$ & - & - & - \\
\hline & 132 & Female & 9 & 5 & 5 & + & + & $>5$ & 4 & - & - & - \\
\hline & 133 & Male & 8 & 5 & 4.6 & + & + & $>5$ & $>5$ & - & - & - \\
\hline & 134 & Male & 8 & 4.9 & 5 & + & + & 2 & $>5$ & - & - & - \\
\hline & 151 & Male & 9 & 5 & 5 & + & + & 5 & 5 & - & - & - \\
\hline & 152 & Male & 7 & 5 & 5 & + & + & 5 & 5 & + & - & + \\
\hline & 153 & Female & 12 & 5 & 5 & + & + & 5 & 3 & - & - & - \\
\hline & 154 & Female & 12 & 5 & 5 & + & + & $>5$ & $>5$ & - & - & - \\
\hline & 155 & Female & 11 & 5 & 4.9 & + & + & 2 & 3 & + & + & + \\
\hline & 157 & Female & 10 & 5 & 5 & + & + & 1 & 2 & - & - & - \\
\hline & 158 & Female & 8 & 5 & 5 & + & + & 1 & 1 & - & - & - \\
\hline & 159 & Male & 12 & 5 & 5 & + & + & 5 & 5 & + & + & + \\
\hline & 160 & Female & 7 & 5 & 5 & + & + & 2 & 2 & + & + & + \\
\hline & 161 & Female & 8 & 5 & 5 & + & + & 5 & 5 & + & + & + \\
\hline & 162 & Male & 9 & 5 & 5 & + & + & 5 & 5 & - & + & + \\
\hline & 163 & Female & 6 & 5 & 5 & + & + & 2 & 3 & - & + & + \\
\hline & 164 & Female & 9 & 5 & 5 & + & + & $>5$ & $>5$ & - & + & + \\
\hline & 165 & Male & 10 & 5 & 5 & + & + & 1 & 2 & - & + & - \\
\hline \multirow[t]{2}{*}{ Total } & \multirow[t]{2}{*}{45 cases } & $\begin{array}{l}\text { Male/ } \\
\text { female }\end{array}$ & Age & \multicolumn{2}{|c|}{ range } & \multicolumn{2}{|c|}{ positive rate } & \multicolumn{2}{|c|}{$\begin{array}{c}\text { Trachoma } \\
\text { follicles } \geqslant 5\end{array}$} & \multicolumn{3}{|c|}{$\begin{array}{c}\text { Both eyes/ } \\
\text { one eye/conjunctival sac }\end{array}$} \\
\hline & & $21 / 24$ & $6-13$ & $4.8-5.1$ & $4.6-5.1$ & $100 \%$ & $100 \%$ & 26 & ses & & $14 /$ & 17 cases \\
\hline
\end{tabular}

a) OD refers to the right eye, and OS refers to the left eye. 


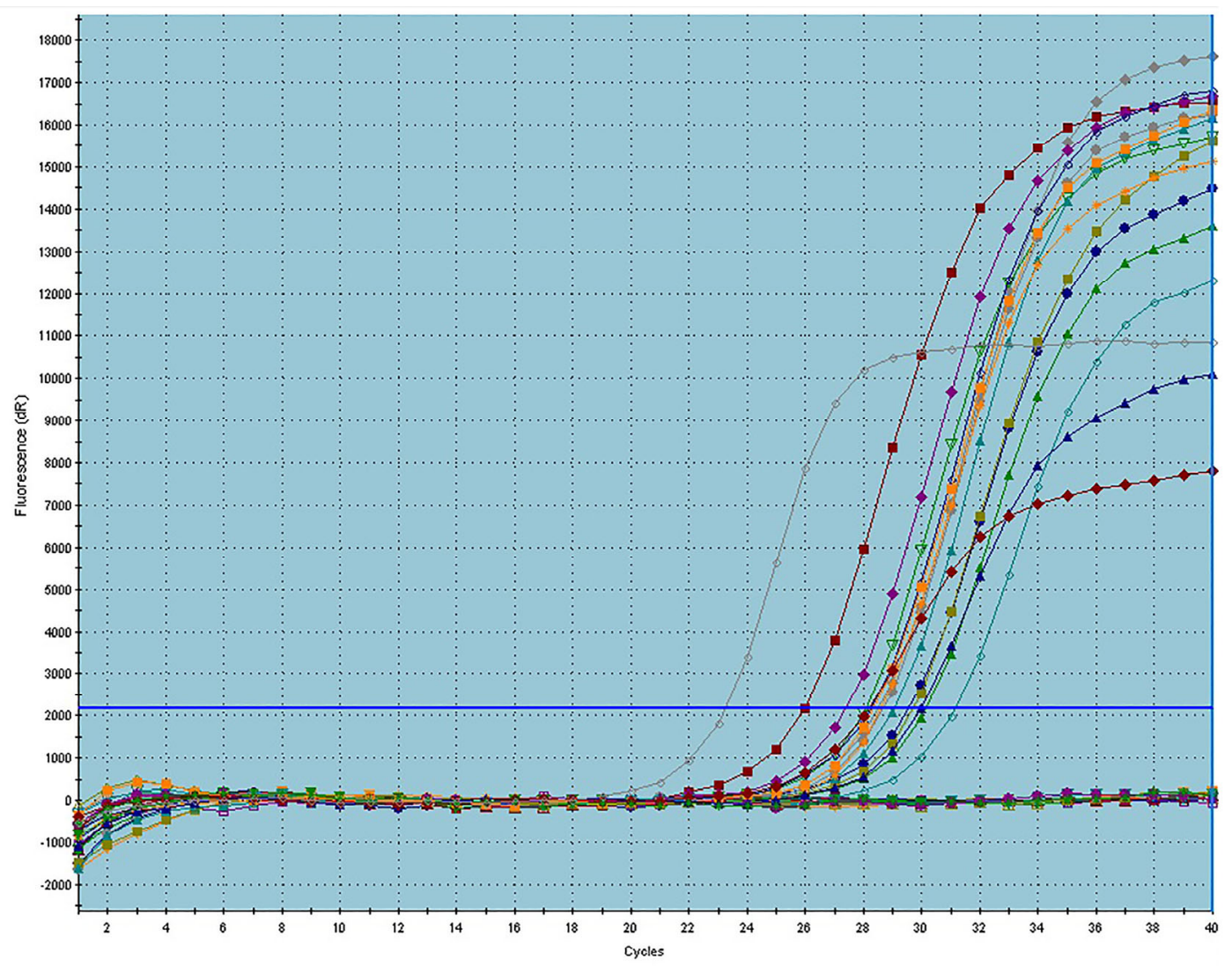

Figure 1 Real-time PCR results for Chlamydia trachomatis. Real-time PCR amplification curves for C. trachomatis. Positive samples appear as S-shaped curves and negative samples as flat curves. The curve for quality control is in red. The copy number of $C$. trachomatis ranged between $2.28 \times 10^{2}$ and $2.90 \times 10^{8}$. According to the standard curve, we defined a high copy number in this study as $>1 \times 10^{5}$, which occurred in $50 \%(13 / 26)$ of the infected $C$. trachomatis-positive students.

example, serotype A is the most common serotype in Tanzania and Brazil (Ishak et al., 2015; Hsieh et al., 2001). The serotype in Morocco is mainly $\mathrm{Ba}$, which is predominantly seen in North Africa (Takourt et al., 2001). Australian studies have shown that serotype $\mathrm{C}$ is the most common serotype in children aged 1-13 years, followed by serotype $\mathrm{Ba}$, whereas in children older than 14 years, even genital-type C. trachomatis (serotypes $\mathrm{D}, \mathrm{F}$, and $\mathrm{K}$ ) may be detected in conjunctival swabs (Porter et al., 2008). Serotypes B and C are the most common serotypes in Asia, as confirmed by several studies (Naito et al., 2009; Takahashi et al., 2007; Wang et al., 2015).

The two newly discovered mutants CQZ-1 and CQZ-2 differ from the serotype $B$ strains reported in the literature. The geographic location at which they were detected was $102.3^{\circ} \mathrm{E}, 35.8^{\circ} \mathrm{N}$, at an altitude of $2,200 \mathrm{~m}$, and all were isolated from Tibetan children. Therefore, we speculate that the two novel mutants may be related to the location, altitude, and host. The serotype was determined from a major outer membrane protein (MOMP) gene. The total length of the ompA gene is $1,182 \mathrm{bp}$, and serotype $\mathrm{B}$ expresses a MOMP of 372 amino acids (Nunes et al., 2009). MOMP has a tertiary structure that includes a $\beta$-fold, and the four variable regions are located in the outer membrane (Mital et al., 2013). Studies have shown that the amino acid differences among serotypes B, A, and C mainly occur in the variable regions. Compared with serotype $\mathrm{A}$, there are 12 , 17,4 , and 13 amino acid differences in serotype B in variable domains VD1, VD2, VD3, and VD4, respectively. When compared with serotype C, serotype B differs in 11, 18,5 , and 15 amino acids in these domains, respectively. In total, there are 10 amino acid differences in the conserved region of ompA between serotype $\mathrm{B}$ and serotype A or C (Baehr et al., 1988). Serotype B has a higher nonsynonymous/synonymous mutation ratio than the other serotypes (greater than the mean value of 0.4) (Joseph et al., 2012). Nunes et al. found that amino acid mutations occur at 12 different sites in the conserved region in serotype $\mathrm{B}$, including six synonymous mutations and six non-synonymous mutations (Nunes et al., 2009). However, all these differ from the mutations detected in the present study. CQZ-1 was found in both primary schools, whereas CQZ-2 was only found in Central Primary School. This school is located in the center of town; therefore, the mobility of this population is higher, which might be the reason for CQZ-2. Compared with the American standard strain ATCC VR-573, mutations occur in both the variable and conserved regions, although there were more mutations in the con- 
Table 2 Comparison of the results in this study and 11 strains of Chlamydia trachomatis serotype B in GenBank ${ }^{\mathrm{a})}$

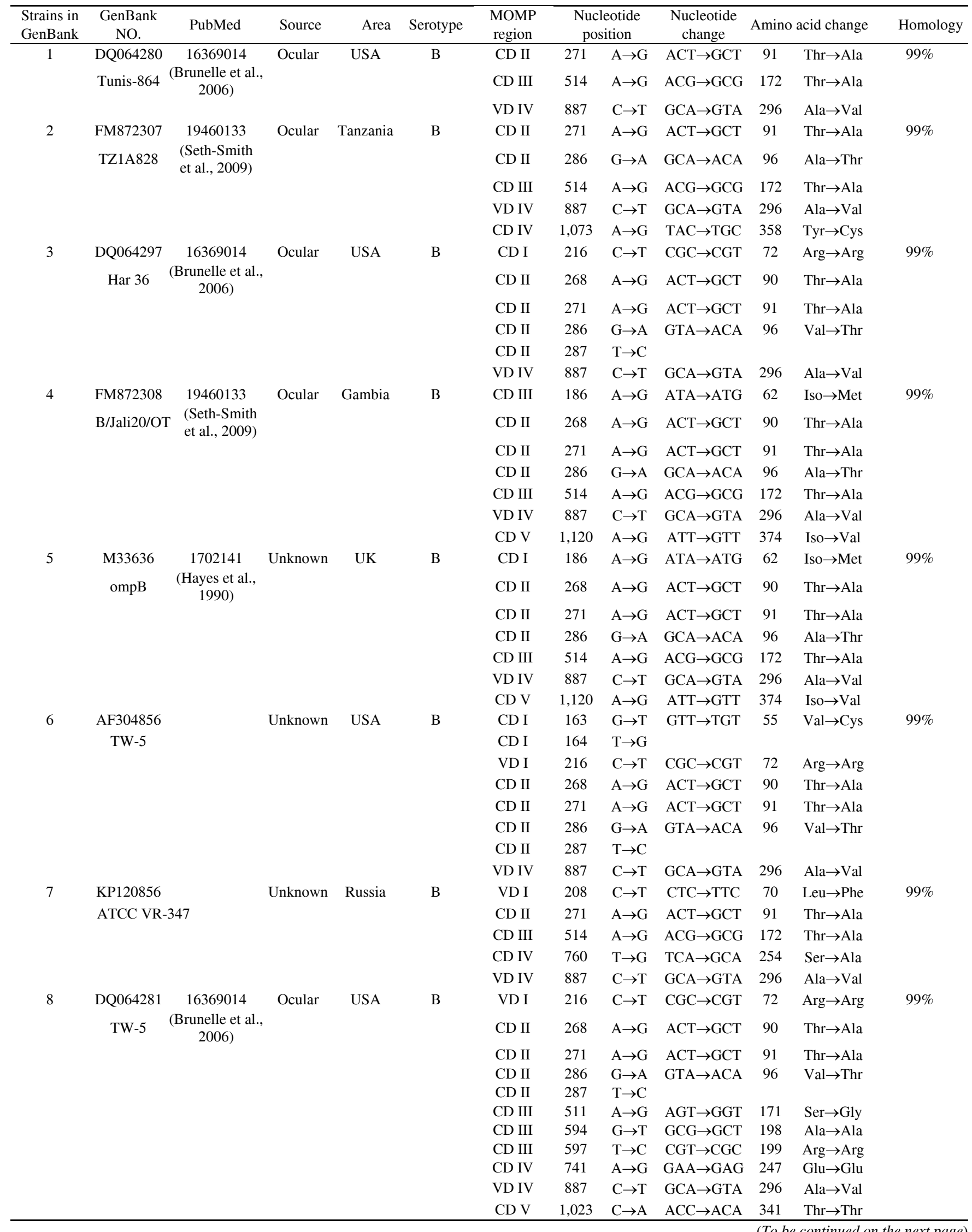




\begin{tabular}{|c|c|c|c|c|c|c|c|c|c|c|c|c|}
\hline \multirow{2}{*}{$\begin{array}{c}\begin{array}{c}\text { Strains in } \\
\text { GenBank }\end{array} \\
9\end{array}$} & \multirow{2}{*}{$\begin{array}{l}\text { GenBank } \\
\text { NO. } \\
\text { JX559518 }\end{array}$} & \multirow[t]{2}{*}{ PubMed } & \multirow{2}{*}{$\begin{array}{c}\text { Source } \\
\text { Ocular } \\
\text { Male } \\
\text { infant }\end{array}$} & \multirow{2}{*}{$\begin{array}{l}\text { Area } \\
\text { USA }\end{array}$} & \multirow{2}{*}{$\frac{\text { Serotype }}{\text { B }}$} & \multirow{2}{*}{$\begin{array}{c}\text { MOMP } \\
\text { region }\end{array}$} & \multicolumn{2}{|c|}{$\begin{array}{l}\text { Nucleotide } \\
\text { position }\end{array}$} & \multirow{2}{*}{$\begin{array}{c}\begin{array}{c}\text { Nucleotide } \\
\text { change }\end{array} \\
\mathrm{CGC} \rightarrow \mathrm{CGT}\end{array}$} & \multicolumn{2}{|c|}{ Amino acid change } & \multirow{2}{*}{$\frac{\text { Homology }}{99 \%}$} \\
\hline & & & & & & & 216 & $\mathrm{C} \rightarrow \mathrm{T}$ & & 72 & $\mathrm{Arg} \rightarrow \mathrm{Arg}$ & \\
\hline & & & & & & CD II & 271 & $\mathrm{~A} \rightarrow \mathrm{G}$ & $\mathrm{ACT} \rightarrow \mathrm{GCT}$ & 91 & $\mathrm{Thr} \rightarrow$ Ala & \\
\hline & & & & & & CD II & 286 & $\mathrm{G} \rightarrow \mathrm{A}$ & $\mathrm{GTA} \rightarrow \mathrm{ACA}$ & 96 & $\mathrm{Val} \rightarrow \mathrm{Thr}$ & \\
\hline & & & & & & VD IV & 887 & $\mathrm{C} \rightarrow \mathrm{T}$ & $\mathrm{GCA} \rightarrow \mathrm{GTA}$ & 296 & $\mathrm{Ala} \rightarrow \mathrm{Val}$ & \\
\hline \multirow[t]{13}{*}{10} & M17342 & 3040664 & HeLa cells & USA & B & CD I & 163 & $\mathrm{G} \rightarrow \mathrm{T}$ & $\mathrm{GTT} \rightarrow \mathrm{TGT}$ & 55 & $\mathrm{Val} \rightarrow$ Cys & $99 \%$ \\
\hline & ompA & $\begin{array}{l}\text { (Stephens } \\
\text { et al., 1987) }\end{array}$ & & & & CD I & 164 & $\mathrm{~T} \rightarrow \mathrm{G}$ & & & & \\
\hline & & & & & & VD I & 216 & $\mathrm{C} \rightarrow \mathrm{T}$ & $\mathrm{CGC} \rightarrow \mathrm{CGT}$ & 72 & $\mathrm{Arg} \rightarrow \mathrm{Arg}$ & \\
\hline & & & & & & CD II & 268 & $\mathrm{~A} \rightarrow \mathrm{G}$ & $\mathrm{ACT} \rightarrow \mathrm{GCT}$ & 90 & $\mathrm{Thr} \rightarrow$ Ala & \\
\hline & & & & & & CD II & 271 & $\mathrm{~A} \rightarrow \mathrm{G}$ & $\mathrm{ACT} \rightarrow \mathrm{GCT}$ & 91 & $\mathrm{Thr} \rightarrow$ Ala & \\
\hline & & & & & & CD II & 287 & $\mathrm{~T} \rightarrow \mathrm{C}$ & & & & \\
\hline & & & & & & CD III & 511 & $\mathrm{~A} \rightarrow \mathrm{G}$ & $\mathrm{AGT} \rightarrow \mathrm{GGT}$ & 171 & Ser $\rightarrow$ Gly & \\
\hline & & & & & & CD III & 585 & $\mathrm{~T} \rightarrow \mathrm{C}$ & $\mathrm{AGT} \rightarrow \mathrm{AGC}$ & 195 & $\mathrm{Ser} \rightarrow \mathrm{Ser}$ & \\
\hline & & & & & & CD III & 594 & $\mathrm{G} \rightarrow \mathrm{T}$ & $\mathrm{GCG} \rightarrow \mathrm{GCT}$ & 198 & $\mathrm{Ala} \rightarrow \mathrm{Ala}$ & \\
\hline & & & & & & CD III & 597 & $\mathrm{~T} \rightarrow \mathrm{C}$ & $\mathrm{CGT} \rightarrow \mathrm{CGC}$ & 199 & $\operatorname{Arg} \rightarrow \operatorname{Arg}$ & \\
\hline & & & & & & CD IV & 741 & $\mathrm{~A} \rightarrow \mathrm{G}$ & $\mathrm{GAA} \rightarrow \mathrm{GAG}$ & 247 & Glu $\rightarrow$ Glu & \\
\hline & & & & & & VD IV & 887 & $\mathrm{C} \rightarrow \mathrm{T}$ & $\mathrm{GCA} \rightarrow \mathrm{GTA}$ & 296 & $\mathrm{Ala} \rightarrow \mathrm{Val}$ & \\
\hline & & & & & & $\mathrm{CD} \mathrm{V}$ & 1,023 & $\mathrm{C} \rightarrow \mathrm{A}$ & $\mathrm{ACC} \rightarrow \mathrm{ACA}$ & 341 & $\mathrm{Thr} \rightarrow \mathrm{Thr}$ & \\
\hline \multirow[t]{10}{*}{11} & FJ261925 & 19929379 & $\begin{array}{l}\text { Vaginal } \\
\text { swab }\end{array}$ & USA & B3 & CD I & 129 & $\mathrm{~T} \rightarrow \mathrm{C}$ & $\mathrm{TTT} \rightarrow \mathrm{TTC}$ & 43 & $\mathrm{Phe} \rightarrow \mathrm{Phe}$ & $99 \%$ \\
\hline & B3/IU-FQ0 & $\begin{array}{c}79 \text { (Batteiger } \\
\text { et al., 2010) }\end{array}$ & $\begin{array}{l}\text { Adoles- } \\
\text { cent girl }\end{array}$ & & & CD I & 154 & $\mathrm{G} \rightarrow \mathrm{A}$ & $\mathrm{GCC} \rightarrow \mathrm{ACC}$ & 52 & $\mathrm{Ala} \rightarrow \mathrm{Thr}$ & \\
\hline & & & & & & CD I & 184 & $\mathrm{G} \rightarrow \mathrm{A}$ & $\mathrm{GTT} \rightarrow \mathrm{ATG}$ & 62 & $\mathrm{Val} \rightarrow \mathrm{Met}$ & \\
\hline & & & & & & CD I & 186 & $\mathrm{~T} \rightarrow \mathrm{G}$ & & & & \\
\hline & & & & & & CD II & 228 & $\mathrm{~T} \rightarrow \mathrm{A}$ & $\mathrm{ACT} \rightarrow \mathrm{ACA}$ & 76 & $\mathrm{Thr} \rightarrow \mathrm{Thr}$ & \\
\hline & & & & & & VD I & 246 & $\mathrm{~T} \rightarrow \mathrm{C}$ & $\mathrm{TTT} \rightarrow \mathrm{TTC}$ & 82 & $\mathrm{Phe} \rightarrow \mathrm{Phe}$ & \\
\hline & & & & & & VD I & 249 & $\mathrm{G} \rightarrow \mathrm{A}$ & $\mathrm{CAG} \rightarrow \mathrm{CAA}$ & 83 & Glu $\rightarrow$ Glu & \\
\hline & & & & & & CD II & 271 & $\mathrm{~A} \rightarrow \mathrm{G}$ & $\mathrm{ACT} \rightarrow \mathrm{GCT}$ & 91 & $\mathrm{Thr} \rightarrow$ Ala & \\
\hline & & & & & & CD III & 514 & $\mathrm{~A} \rightarrow \mathrm{G}$ & $\mathrm{ACG} \rightarrow \mathrm{GCG}$ & 172 & $\mathrm{Thr} \rightarrow$ Ala & \\
\hline & & & & & & VD IV & 887 & $\mathrm{C} \rightarrow \mathrm{T}$ & $\mathrm{GCA} \rightarrow \mathrm{GTA}$ & 296 & $\mathrm{Ala} \rightarrow \mathrm{Val}$ & \\
\hline
\end{tabular}

a) The table shows the results for the comparison of 26 cases of Chlamydia trachomatis and 11 cases of Chlamydia trachomatis with serotype B in GenBank. The mutated nucleotide site and corresponding amino acid change in each strain are given. CD, conserved domain. VD, variable domain.

served region, which might be attributable to evolution.

This study was performed with culturing and deep sequencing $C$. trachomatis isolates. The ompA serotype of $C$. trachomatis and its novel mutations were identified in this study. The functions of the mutated proteins may have changed, strengthening the virulence or pathogenicity of the strain. However, the expression of the translated protein was not examined in this study and must be addressed in future research.

\section{SUBJECTS AND METHODS}

\section{Subjects}

Specimens were collected from the eyes of children enrolled at Jianshetang Primary School and Central Primary School in the Galeng township in Qinghai Xunhua County on May 25 and December 31, 2015, respectively (the location is shown in Figure 3). The diagnostic criteria for trachoma were the simplified trachoma grading system developed by the WHO (Thylefors et al., 1987).

Samples were collected from the upper palpebral conjunctiva and conjunctival sac (one sample per site) of students with trachoma. The specific procedure was as follows: the upper eyelid was exposed with gentle turning, and a Copan swab was wiped horizontally within the range of the trachoma follicles with slight pressure four times, with a rotation of $90^{\circ}$ each time. The lower eyelid conjunctival sac was then exposed, and swab samples were obtained in the same way. The swabs were placed in matched sample tubes, stored with an ice bag, and transported to Beijing Tongren Hospital by air within $24 \mathrm{~h}$. 


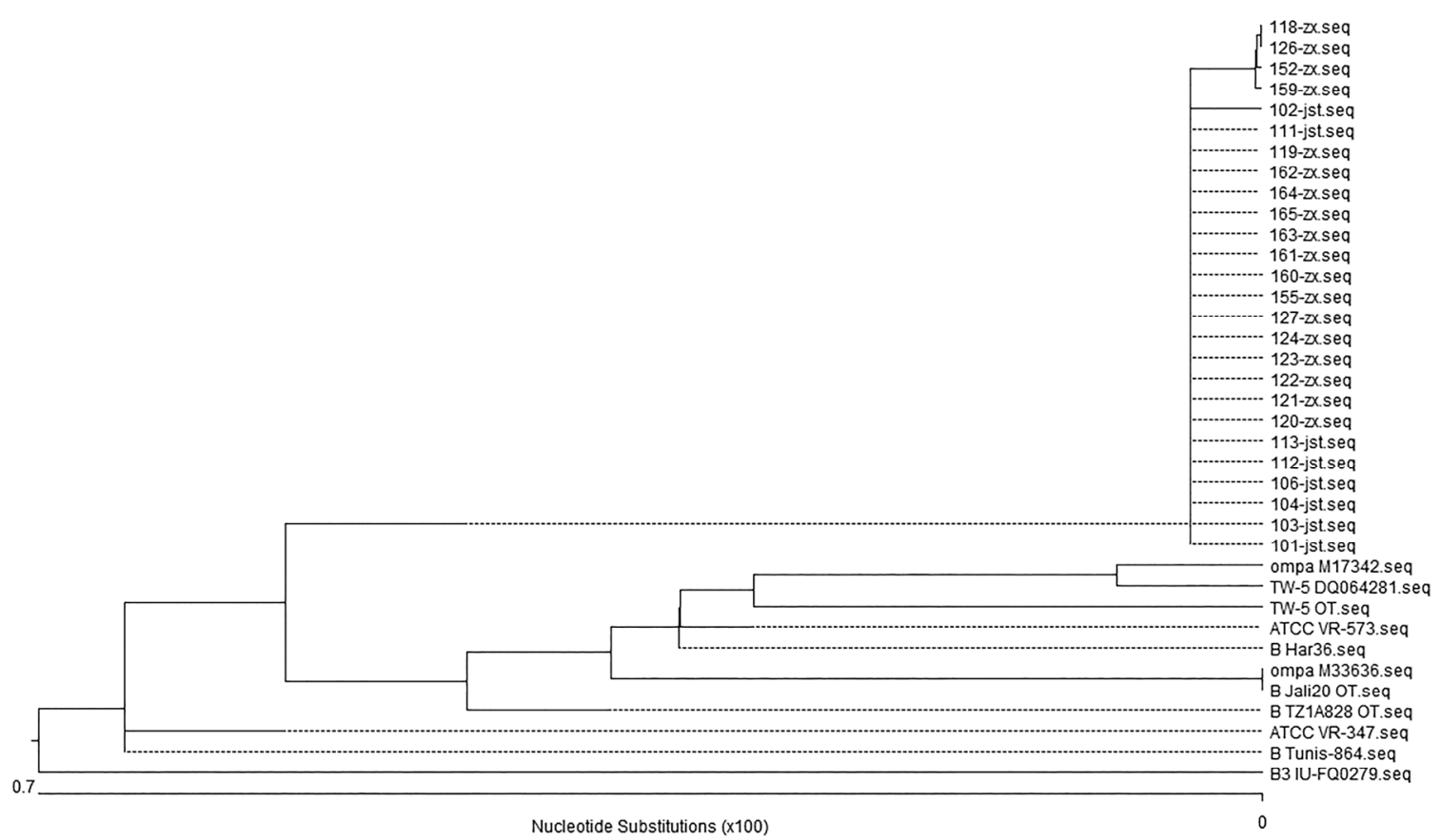

Figure 2 Homology analysis of 26 strains in this study and 11 strains of Chlamydia trachomatis with serotype B in GenBank. The phylogenetic analyses showed strain segregation. The 11 serotype B strains available in GenBank from the United States, the United Kingdom, Tanzania, the Gambia, and Russia are divided into three clusters. Among them, TW-5 DQ064281, ompA M17342, TW-5 OT, ATCC VR-573, B Har36, ompA M33636, B Jali20 OT, and B TZ1A828 OT belong to one cluster, while ATCC VR-347 and B Tunis-864 belong to another cluster. C. trachomatis in this study had higher homology with the latter cluster. B3 IU-FQ0279, which is from the United States, was obtained from the reproductive tract of a female adolescent, and this isolate appears as a singleton node.

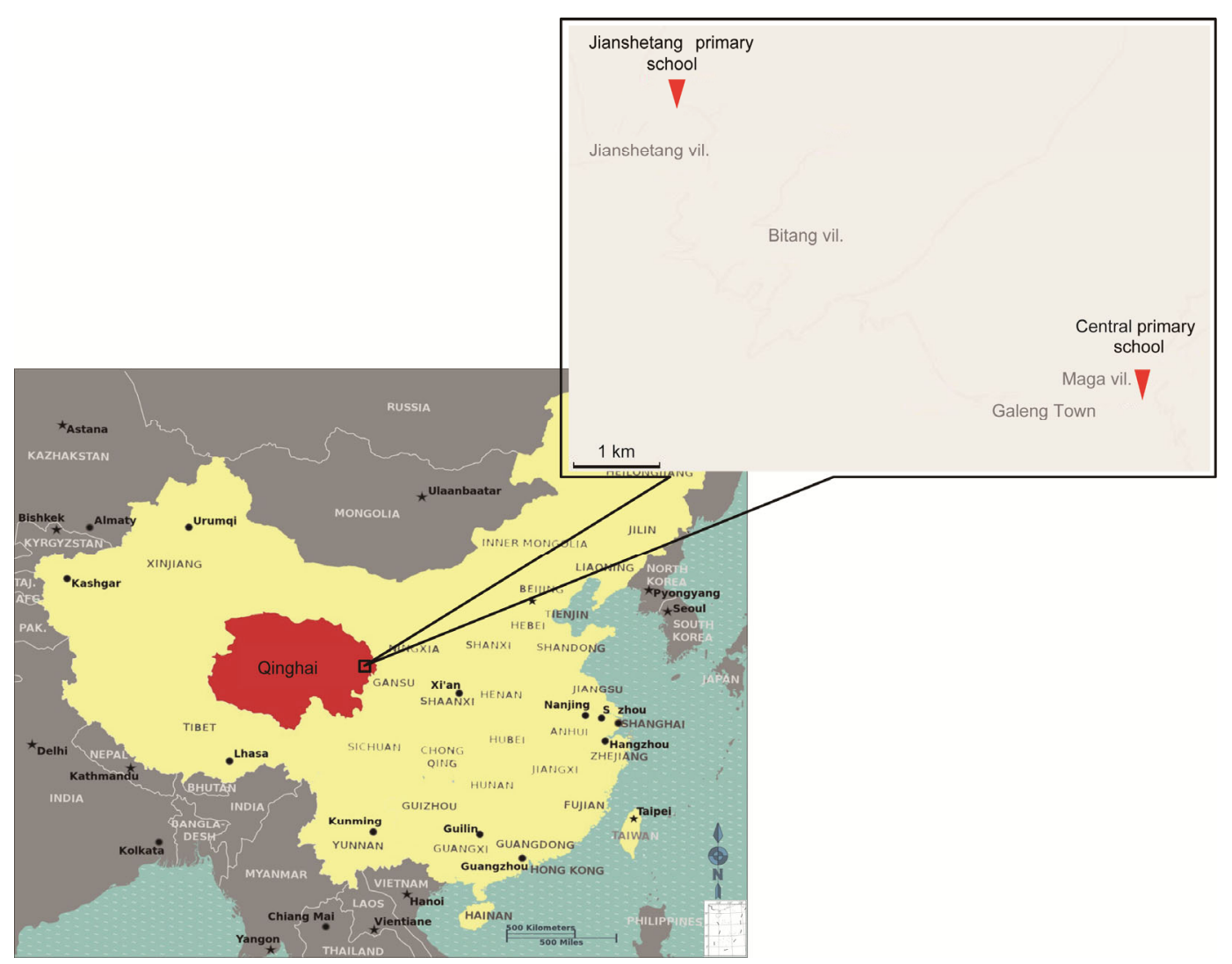

Figure 3 Geographic relationship of Jianshetang Primary School and Central Primary School. The two primary schools are located in the Tibetan township of Galeng in Qinghai Haidong Salar Autonomous County, at an altitude of 2,200 m, with a straight-line distance of about $6 \mathrm{~km}$ between them. 


\section{Reagents and instruments}

Nested PCR primers were synthesized, and the target fragment was sequenced by the Beijing Sinogenomax Research Center Co., Ltd. The reagents and instruments used were a real-time PCR detection kit for $C$. trachomatis (Shanghai Zhijiang Biotechnology Co., Ltd.), Sorvall ${ }^{\mathrm{TM}}$ ST 8 (Thermo Fisher Scientific Co., USA), The PowerPac ${ }^{\mathrm{TM}}$ Universal power supply (Bio-Rad Laboratories, Inc., USA), T100 Thermal Cycler (Bio-Rad Laboratories, Inc.), $\mathrm{M} \times 3000 \mathrm{P}^{\mathrm{TM}}$ real-time fluorescent quantitative PCR instrument (Agilent Technologies, USA), and FLOQS wabs ${ }^{\mathrm{TM}}$ (Copan, Italy).

\section{Methods}

\section{Real-time PCR detection of $C$. trachomatis}

Nucleic acid extraction, PCR, and the interpretation of the results were performed using a real-time PCR kit to detect C. trachomatis obtained from Shanghai Zhijiang Biotechnology Co., Ltd. The cycle threshold (CT) was 38, where $<38$ meant positivity and >40 meant negativity. According to the standard curve, a high copy number in this study was deemed to be more than $1 \times 10^{5}$, with a CT value of $<28.5$.

\section{Sequencing the ompA gene after nested PCR amplifica- tion to identify the serotype}

The C. trachomatis ompA gene was amplified with nested PCR from the positive samples obtained by the primary screening. The ompA gene was located at 778,879-780,060 bp in the $C$. trachomatis genome, with a length of 1,182 bp, including the variable regions (VS1, VS2, VS3, and VS4) and conserved domains. The amplification primers are shown in Table 3 (Bandea et al., 2001). The amplification products were $1,315 \mathrm{bp}$, including the full-length $C$. trachomatis ompA gene $(1,182 \mathrm{bp})$. The structure of the $C$. trachomatis ompA gene and the positions of the primers are shown in Figure 4. The primers used for sequencing were synthesized according to the literature (Table 4) (Bandea et al., 2001), and the samples were sequenced by Beijing Sinogenomax Research Center Co., Ltd. A sequence alignment was constructed with NCBI BLAST to determine the serotype of the C. trachomatis isolates.

Table 3 Amplification primers for the ompA gene of Chlamydia trachomatis

\begin{tabular}{lll}
\hline Primer & $5^{\prime} \rightarrow 3^{\prime}$ sequence & Amplified fragment \\
\hline Outer primer & GGACATCTTGTCTGGCTTTAACT & $1,503 \mathrm{bp}$ \\
& GCGCTCAAGTAGACCGATATAGTA & $1,315 \mathrm{bp}$ \\
\hline \multirow{2}{*}{ Inner primer } & GTCCCGCCAGAAAAAGATAG & \\
& CCAGAAACACGGATAGTGTTATTA & \\
\hline
\end{tabular}

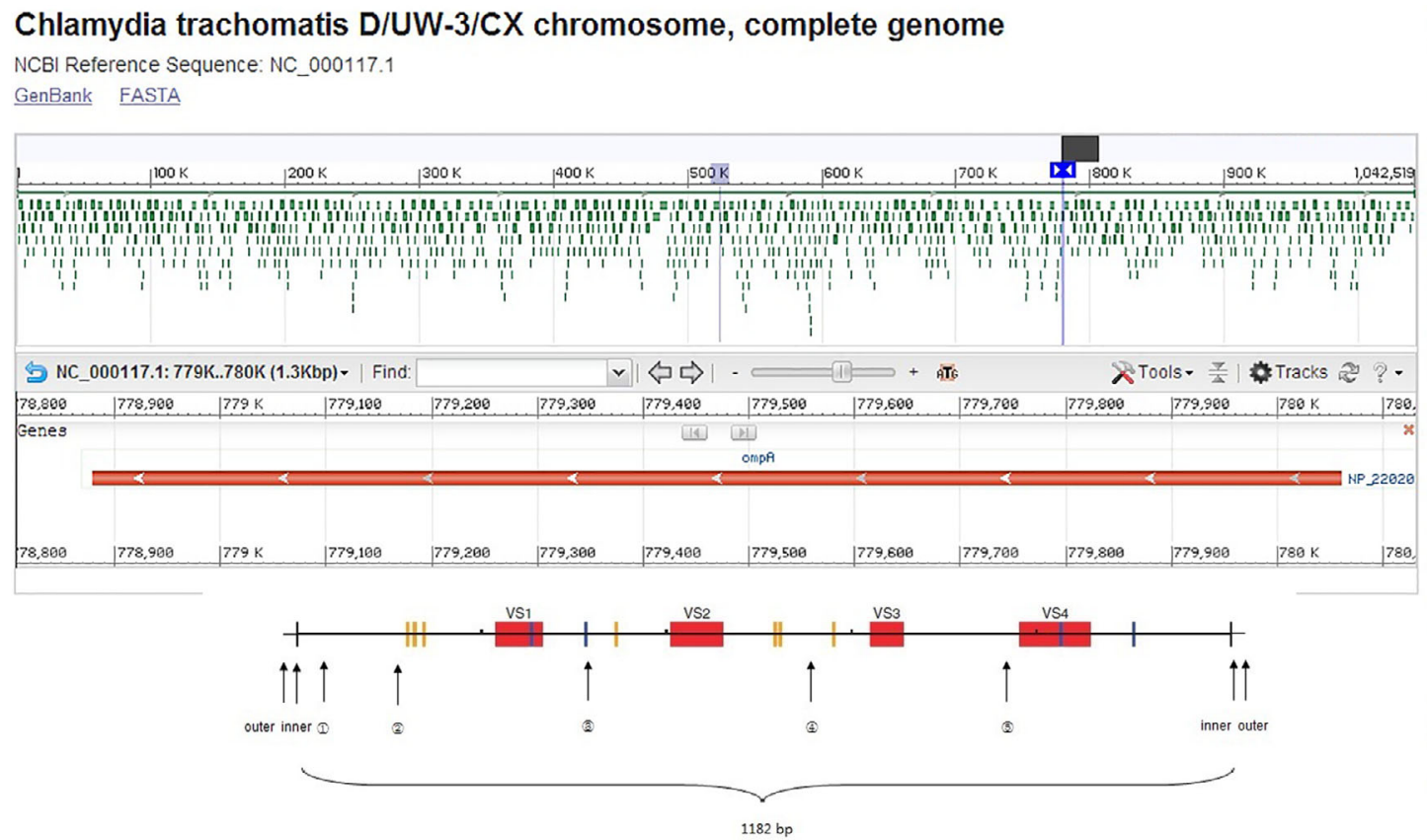

Figure 4 Structure of Chlamydia trachomatis ompA gene and primer-binding sites. "Inner" and "outer" refer to the inner amplification primer and outer amplification primer used for nested PCR, respectively; (1) to (5) refer to the five sequencing primers. The upper panel shows the whole genomic sequence of $C$. trachomatis. The lower panel is a schematic diagram of the structure of the ompA gene (Harris et al., 2012); the binding sites of the inner and outer primers and sequencing primers $1-5$ are shown. 
Table 4 Sequencing primers for the ompA gene of Chlamydia trachomatis

\begin{tabular}{cl}
\hline Primer name & $5^{\prime} \rightarrow 3^{\prime}$ sequence \\
\hline CT40F & ATAGCGAGCACAAAGAGAGC \\
CT160F & ACCACTTGGTGTGACGCTATCCAG \\
CT419F & TGGGATCGTTTTGATGTATT \\
CT662F & ACGTTAGGAGCTTCTTTCCAATA \\
CT902F & TCCTTACATTGGAGTTAAATGGTC \\
\hline
\end{tabular}

\section{Homology analysis of the ompA gene}

Homology analysis of the ompA gene was performed on the gene sequences using the DNAMAN (8.0 version) software to determine the characteristics of the $C$. trachomatis ompA gene. After ompA was sequenced, the serotypes were confirmed by NCBI BLAST comparison, and any novel mutations relative to all the serotype B $C$. trachomatis sequences in GenBank were identified. The genetic variants were submitted to GenBank under accession numbers KU737520 and KU737521.

\section{Statistical methods}

The SPSS 22.0 statistical package(IBM Corp., USA) was used for the statistical analysis of all results. A difference was deemed statistically significant if $P<0.05$.

Compliance and ethics The author(s) declare that they have no conflict of interest.

Acknowledgements Our sincere gratitude goes to the Qinghai Province People's Government and Department of Health, the Xunhua County Government in Qinghai Province and the Department of Health, and the Qinghai Province People's Hospital for their full support.

Baehr, W., Zhang, Y., Joseph, T., Su, H., Nano, F.E., Everett, K.D., and Caldwell, H.D. (1988). Mapping antigenic domains expressed by Chlamydia trachomatis major outer membrane protein genes. Proc Natl Acad Sci USA 85, 4000-4004.

Bandea, C.I, Kubota, K., Brown, T.M., Kilmarx, P.H., Bhullar, V., Yanpaisarn, S., Chaisilwattana, P., Siriwasin, W., and Black, C.M. (2001). Typing of Chlamydia trachomatis strains from urine samples by amplification and sequencing the major outer membrane protein gene (omp1). Sex Transm Infect 77, 419-422.

Batteiger, B.E., Tu, W., Ofner, S., Van Der Pol, B., Stothard, D.R., Orr, D.P., Katz, B.P., and Fortenberry, J.D. (2010). Repeated Chlamydia trachomatis genital infections in adolescent women. J Infect Dis 201, 42-51.

Seth-Smith, H.M., Harris, S.R., Persson, K., Marsh, P., Barron, A., Bignell, A., Bjartling, C., Clark, L., Cutcliffe, L.T., Lambden, P.R., Lennard, N., Lockey, S.J., Quail, M.A., Salim, O., Skilton, R.J., Wang, Y., Holland, M.J., Parkhill, J., Thomson, N.R., and Clarke, I.N. (2009). Co-evolution of genomes and plasmids within Chlamydia trachomatis and the emergence in Sweden of a new variant strain. BMC Genomics 10, 239.

Brunelle, B.W., and Sensabaugh, G.F. (2006). The ompA gene in Chlamydia trachomatis differs in phylogeny and rate of evolution from other regions of the genome. Infect Immun 74, 578-585.

Burton, M.J., Holland, M.J., Makalo, P., Aryee, E.A., Sillah, A., Cohuet, S., Natividad, A., Alexander, N.D., Mabey, D.C., and Bailey, R.L. (2010). Profound and sustained reduction in Chlamydia trachomatis in The Gambia: a five-year longitudinal study of trachoma endemic com- munities. PLoS Negl Trop Dis 4, 10

Harris, S.R., Clarke, I.N., Seth-Smith, H.M., Solomon, A.W., Cutcliffe, L.T., Marsh, P., Skilton, R.J., Holland, M.J., Mabey, D., Peeling, R.W., Lewis, D.A., Spratt, B.G., Unemo, M., Persson, K., Bjartling, C., Brunham, R., de Vries, H.J., Morré, S.A., Speksnijder, A., Bébéar, C.M., Clerc, M., de Barbeyrac, B., Parkhill, J., and Thomson, N.R. (2012). Whole-genome analysis of diverse Chlamydia trachomatis strains identifies phylogenetic relationships masked by current clinical typing. Nat Genet 44, 413-419, S411.

Hayes, L.J, Pickett, M.A., Conlan, J.W., Ferris, S., Everson, J.S., Ward, M.E., and Clarke, I.N. (1990). The major outer-membrane proteins of Chlamydia trachomatis serovars A and B: intra-serovar amino acid changes do not alter specificities of serovar- and $\mathrm{C}$ subspecies-reactive antibody-binding domains. J Gen Microbiol 136, 1559-1566.

Hsieh, Y.H., Bobo, L.D., Quinn, T.C., and West, S.K. (2001). Determinants of trachoma endemicity using Chlamydia trachomatis ompA DNA sequencing. Microbes Infect 3, 447-458.

Ishak, Mde.O., Costa, M.M., de Almeida, N.C., Santiago, A.M., de Brito, W.B., Vallinoto, A.C., Azevedo, V.N., and Ishak, R. (2015). Chlamydia trachomatis serotype A infections in the Amazon region of Brazil: prevalence, entry and dissemination. Rev Soc Bras Med Trop 48, $170-174$.

Joseph, S.J., Didelot, X., Rothschild, J., de Vries, H.J., Morre, S.A., Read, D., and Dean, D. (2012). Population genomics of Chlamydia trachomatis: insights on drift, selection, recombination, and population structure. Mol Biol Evol 29, 3933-3946.

King, J.D., Odermatt, P., Utzinger, J., Ngondi, J., Bamani, S., Kamissoko, Y., Boubicar, K., Hassan, A.S., Nwobi, B.C., Jip, N., Amnie, A., Teferi, T., Mosher, A.W., Stewart, A.E., Cromwell, E.A., and Emerson P.M. (2013). Trachoma among children in community surveys from four African countries implications of using school surveys for evaluating prevalence. Int Health 5, 280-287.

Last, A.R., Burr, S.E., Weiss, H.A., Harding-Esch, E.M., Cassama, E., Nabicassa, M., Mabey, D.C., Holland, M.J., and Bailey, R.L. (2014). Risk factors for active trachoma and ocular Chlamydia trachomatis infection in treatment-naive trachoma-hyperendemic communities of the Bijagos Archipelago, Guinea Bissau. PLoS Negl Trop Dis 8, 2900.

Mital, J., Miller, N.J., Dorward, D.W., Dooley, C.A., and Hackstadt, T. (2013). Role for chlamydial inclusion membrane proteins in inclusion membrane structure and biogenesis. PLoS One 8, 63426.

Naito, T., Aoki, K., Ohguchi, T., Ohgami, K., Ohno, S., Shiot, H., Shrestha, J.K., and Upadhyay, M.P. (2009). Pathogenesis of infectious conjunctivitis in Nepal. Nippon Ganka Gakkai Zasshi 113, 1088-1091.

Nigusie, A., Berhe, R., and Gedefaw, M. (2015). Prevalence and associated factors of active trachoma among children aged 1-9 years in rural communities of GonjiKolella district, West Gojjam zone, North West Ethiopia. BMC Res Notes 8, 641.

Nunes, A., Borrego, M.J., Nunes, B., Florindo, C., and Gomes, J.P. (2009). Evolutionary dynamics of ompA, the gene encoding the Chlamydia trachomatis key antigen. J Bacteriol 191, 7182-7192.

Porter, M., Mak, D., Chidlow, G., Harnett, G.B., and Smith, D.W. (2008). The molecular epidemiology of ocular Chlamydia trachomatis infections in Western Australia: implications for trachoma control. Am J Trop Med Hyg 78, 514-517.

Seth-Smith, H.M., Harris, S.R., Persson, K., Marsh, P., Barron, A., Bignell, A., Hayes, L.J., Pickett, M.A., Conlan, J.W., Ferris, S., Everson, J.S., Ward, M.E., and Clarke, I.N. (1990). The major outer-membrane proteins of Chlamydia trachomatisserovars A and B: intra-serovar amino acid changes do not alter specificities of serovar- and $\mathrm{C}$ subspecies-reactive antibody-binding domains. J Gen Microbiol 136, 1559-1566.

Shattock, A.J., Gambhir, M., Taylor, H.R., Cowling, C.S., Kaldor, J.M., and Wilson, D.P. (2015). Control of trachoma in Australia: a model based evaluation of current interventions. PLoS Negl Trop Dis 9, e0003474.

Stephens, R.S., Sanchez-Pescador, R., Wagar, E.A., Inouye, C., and Urdea, M.S. (1987). Diversity of Chlamydia trachomatis major outer membrane protein genes. J Bacteriol 169, 3879-3885. 
Takahashi, S., Yamazaki, T., Satoh, K., Inoue, M., Takahashi, S., Ishihara, O., Oka, Y., Horiguchi, Y., Okuwaki, Y., Suzuki, S., and Kishimoto, T. (2007). Longitudinal epidemiology of Chlamydia trachomatisserovars in female patients in Japan. Jpn J Infect Dis 60, 374-376.

Takourt, B., de Barbeyrac, B., Khyatti, M., Radouani, F., Bebear, C., Dessus-Babus, S., Bebear, C., and Benslimane, A. (2001). Direct genotyping and nucleotide sequence analysis of VS1 and VS2 of the Omp1 gene of Chlamydia trachomatis from Moroccan trachomatous speci- mens. Microbes Infect 3, 459-466.

Taylor, H.R., Burton, M.J., Haddad, D., West, S., and Wright, H. (2014). Trachoma. Lancet 384, 2142-2152.

Thylefors, B., Dawson, C.R., Jones, B.R., West, S.K., and Taylor, H.R. (1987). A simple system for the assessment of trachoma and its complications. Bull World Health Organ 65, 477-483.

Wang, N., Hu, A., and Taylor, H.R. (2015). Trachoma. (Beijing: People's Medical Publishing House), pp. 50.

Open Access This article is distributed under the terms of the Creative Commons Attribution License which permits any use, distribution, and reproduction in any medium, provided the original author(s) and source are credited.

\section{SUPPORTINGINFORMATION}

Figure S1 Comparison of the 26 strains of Chlamydia trachomatis isolated in this study and 11 serotype B strains recorded in GenBank.

The supporting information is available online at life.scichina.com and link.springer.com. The supporting materials are published as submitted, without typesetting or editing. The responsibility for scientific accuracy and content remains entirely with the authors. 